\title{
A PESQUISA DAS LÍNGUAS ESLAVAS NO CENÁRIO DA DIVERSIDADE LINGUÍSTICA NA REGIÃO SUL BRASIL
}

\author{
Myrna Estella Iachinski Mendes
}

Submetido em 07 de maio de 2019.

Aceito para publicação em 27 de julho de 2019.

Cadernos do IL, Porto Alegre, n. ${ }^{\circ}$ 59, outubro. p. 271-290.

\section{POLÍTICA DE DIREITO AUTORAL}

Autores que publicam nesta revista concordam com os seguintes termos:

1. Os autores mantêm os direitos autorais e concedem à revista o direito de primeira publicação, com o trabalho simultaneamente licenciado sob a Creative Commons Attribution License, permitindo o compartilhamento do trabalho com reconhecimento da autoria do trabalho e publicação inicial nesta revista.

2. Os autores têm autorização para assumir contratos adicionais separadamente, para distribuição não exclusiva da versão do trabalho publicada nesta revista (ex.: publicar em repositório institucional ou como capítulo de livro), com reconhecimento de autoria e publicação inicial nesta revista.

3. Os autores têm permissão e são estimulados a publicar e distribuir seu trabalho online (ex.: em repositórios institucionais ou na sua página pessoal) a qualquer ponto antes ou durante o processo editorial, já que isso pode gerar alterações produtivas, bem como aumentar o impacto e a citação do trabalho publicado.

4. Os autores estão conscientes de que a revista não se responsabiliza pela solicitação ou pelo pagamento de direitos autorais referentes às imagens incorporadas ao artigo. A obtenção de autorização para a publicação de imagens, de autoria do próprio autor do artigo ou de terceiros, é de responsabilidade do autor. Por esta razão, para todos os artigos que contenham imagens, o autor deve ter uma autorização do uso da imagem, sem qualquer ônus financeiro para os Cadernos do IL.

\section{POLÍTICA DE ACESSO LIVRE}

Esta revista oferece acesso livre imediato ao seu conteúdo, seguindo o princípio de que disponibilizar gratuitamente o conhecimento científico ao público proporciona sua democratização.

http://seer.ufrgs.br/cadernosdoil/index

Terça-feira, 29 de outubro de 2019. 


\title{
A PESQUISA DAS LÍNGUAS ESLAVAS NO CENÁRIO DA DIVERSIDADE LINGUÍSTICA NA REGIÃO SUL BRASIL
}

\author{
THE SEARCH OF SLAVER LANGUAGES IN THE \\ SCENARIO OF LINGUISTIC DIVERSITY OF BRAZIL
}

\author{
Myrna Estella Iachinski Mendes*
}

\begin{abstract}
RESUMO: O presente artigo analisa o estado da arte sobre línguas de imigração eslava em contato com o português no contexto da diversidade linguística brasileira. O estudo justifica-se por ampliar o foco para complementação e compartilhamento de resultados e chegar a uma visão consistente do comportamento linguístico em relação às linguas eslavas. O artigo inicia com a análise dos imigrantes eslavos (poloneses, ucranianos, russos) na perspectiva histórica de imigração. Na sequência, priorizam-se estudos descritivos, com enfoque sociolinguístico, plurilinguístico-dialetológico ou de sociologia da linguagem, levando às seguintes considerações: 1) a necessidade de formação de pesquisadores para as línguas eslavas; 2) mapeamento da presença das línguas eslavas; 3) mapeamento das diferentes variedades eslavas presentes no Brasil.
\end{abstract}

PALAVRAS-CHAVE: Imigração eslava; língua; multilinguismo.

ABSTRACT: This paper analyzes the state of the art about immigration languages in contact with Portuguese in the context of Brazilian linguistic diversity. The study is justified by broadening the focus to complement and study the results, and to arrive at a consistent view of linguistic behavior in Slavic language languages. The article begins with an analysis of Slavic immigrants (Polish, Ukrainian, Russian) from the perspective of immigration. Then, descriptive studies with a sociolinguistic, plurilingual-dialectological or language sociology approach led by these considerations are prioritized: 1) the need for training researchers for Slavic languages; 2) mapping of the presence of Slavic languages; 3) mapping of different Slavic varieties present in Brazil.

KEYWORDS: Slavic immigration; language; multilingualism.

\section{Introdução}

Línguas de imigração pressupõem, por definição, um movimento migratório de uma matriz de origem (ponto de partida) para um novo meio (área no Brasil), em contato não apenas com o português como também com outras línguas, normalmente de outros imigrantes que não procedem da mesma matriz de origem (ALTENHOFEN \& THUN, 2016). Como esse movimento e esse desenvolvimento no novo meio conta já com um período de tempo razoável, essas línguas de imigração também estão, consequentemente, sujeitas à variação e mudança linguística, bem como à manutenção ou substituição pela língua majoritária do novo meio. Junto com a língua, imigra a cultura, incluindo hábitos, aspectos materiais e práticas sociais particulares.

As teses, dissertações, artigos e mapas que tratam de aspectos linguísticos têm descrito o cenário linguístico-cultural desses imigrantes, tanto na oralidade quanto na escrita. As línguas eslavas chegaram ao Brasil, sobretudo, a partir da segunda metade do

\footnotetext{
* Doutoranda do Curso de Letras da Universidade Federal do Rio Grande do Sul - UFRGS. Orientador Cléo Vilson Altenhofen. E-mail: cvalten@ufrgs.br
} 
séc. XIX, anos 1860 e 1889, e se estenderam até 1950. Como primeiros núcleos de colonização polonesa tem-se o ano de 1847, poloneses que chegaram ao Espírito Santo, provenientes da Prússia Oriental e da Silésia. A presença russa é registrada em localidades como Palmeiras, no Paraná, em 1870.

No entanto, os Russos vieram em três levas, a partir, também, de 1847 (BISTENSKO, 2006, p.11). Os primeiros imigrantes ucranianos vieram por volta de 1895 e 1897 quando, segundo Garin (2010, p.11), cerca de 20 mil imigrantes ucranianos aportaram no porto de Santos e de Paranaguá. Os primeiros direcionaram-se a Prudentópolis e Malet Pr., considerados os primeiros imigrantes ucranianos que se instalaram no Brasil. Ao todo, estima-se, de acordo com o IBGE de 1940/1950, um total de $0,41 \%$ de bilíngues, português-língua eslava, sendo que o maior contingente $(36,9 \%$ dos falantes de línguas eslavas) se concentrava no Paraná e 27,42\% no Rio Grande do Sul. São números baixos, comparando com as cifras de alemães e italianos, e que, ainda, sofrem da dificuldade de, muitas vezes, distinguir seus falantes como poloneses, ucranianos ou russos, tendo em vista as diferentes formas de hibridismo que os caracterizam. De qualquer forma, mais justo é considerar as territorialidades atingidas por esses grupos que, seguramente, abrangem uma área bem superior à atual Polônia. Diante dessas circunstâncias, manter a língua é um desafio aos que aqui se constituíram, em contato com uma língua e cultura de base luso-brasileira tão distinta.

No presente artigo, analisamos, inicialmente, os aspectos históricos apontados pelos estudos como relevantes para a descrição das línguas de imigração eslava em contato com o português, no Sul do Brasil, em especial do polonês. Entre esses aspectos estão às condições de assentamento no novo meio, a territorialidade da língua, assim constituída, bem como aspectos da socialização e integração no contexto brasileiro.

Em um segundo momento, também, constitui um dos focos de análise deste artigo o levantamento de documentos escritos, teses, dissertações e artigos produzidos sobre essas línguas eslavas. O objetivo é abstrair sinteticamente os principais resultados desses estudos, identificando aí a necessidade de novas perspectivas teóricas, para compreender o contexto das línguas eslavas no atual cenário brasileiro.

\section{Os imigrantes eslavos no Sul do Brasil}

Ao analisar as pesquisas sobre línguas de imigração, é inconcebível não considerar os estudos dos processos históricos desses imigrantes. Sendo assim, vale ordenar esses estudos em ordem cronológica, no período de 1956 a 2010, para reconstruir o itinerário desses imigrantes, ou seja, a rota dos grupos de origem eslava que ocuparam terras brasílicas, especificamente, na região Sul do Brasil. O Quadro 1 resume as principais contribuições de ordem histórico-social, as áreas abrangidas e tópicos de análise. 
Quadro 1 - Quadro dos estudos com foco na história da imigração de eslavos ao Brasil, em ordem cronológica

\begin{tabular}{|c|c|c|c|}
\hline Estudo & $\begin{array}{l}\text { Área de } \\
\text { abrangência }\end{array}$ & Tópicos de análise & Tipo de estudo \\
\hline $\begin{array}{l}\text { Gardolinski } \\
(1956)\end{array}$ & RS & Os imigrantes poloneses no RS- & $\begin{array}{l}\text { A contribuição } \\
\text { dos poloneses na } \\
\text { formação do RS }\end{array}$ \\
\hline $\begin{array}{l}\text { Gardolinski } \\
(1977)\end{array}$ & RS & A formação das escolas polonesas & $\begin{array}{c}\text { Mapeamento } \\
\text { das escolas } \\
\text { quantificando-as no RS }\end{array}$ \\
\hline $\begin{array}{l}\text { Goulart } \\
\text { (1984) }\end{array}$ & $\mathrm{SC}$ & $\begin{array}{l}\text { Formação da Colônia Príncipe } \\
\text { Dom Pedro }\end{array}$ & $\begin{array}{l}\text { Os primeiros } \\
\text { poloneses em Santa } \\
\text { Catarina }\end{array}$ \\
\hline $\begin{array}{l}\text { Gluchowski } \\
(2005)\end{array}$ & PR & $\begin{array}{l}\text { Os poloneses e os processos de } \\
\text { colonização no Brasil }\end{array}$ & $\begin{array}{l}\text { O cenário dos } \\
\text { imigrantes poloneses no } \\
\text { Paraná e no Brasil }\end{array}$ \\
\hline $\begin{array}{l}\text { Martins } \\
(2008)\end{array}$ & PR & $\begin{array}{l}\text { Colonização eslava a partir de } \\
1937\end{array}$ & $\begin{array}{c}\text { Gleba } \\
\text { formalizada para receber } \\
\text { imigrantes em } \\
\text { Arapongas PR. }\end{array}$ \\
\hline $\begin{array}{l}\text { Iarochinski } \\
(2010)\end{array}$ & PR & $\begin{array}{l}\text { A identidade dos imigrantes } \\
\text { poloneses no Brasil }\end{array}$ & $\begin{array}{l}\text { Polaco ou } \\
\text { polonês? }\end{array}$ \\
\hline
\end{tabular}

\subsection{Presença eslava no Rio Grande do Sul}

Em seu estudo sobre Imigração e Colonização Polonesa, Gardolinski (1956) chama a atenção para as fronteiras da Polônia, ocupada em parte pelas potências econômicas da Prússia, Rússia e Áustria. Esta divisão interna está na base dos processos migratórios de poloneses para o Brasil, especificamente com a vinda ao Rio Grande do Sul, a partir de 1890. Em vista da escassez de documentos, afirma-se o pesquisador que, no entanto, a imigração polonesa ocorreu apenas após a primeira "leva" de imigrantes italianos estabelecidos no Rio Grande do Sul.

[...] Conta-nos a História que, enquanto o primeiro grupo de imigrantes italianos aportava, em 1875, já existiam referências aos colonos poloneses, no Estado do Rio Grande do Sul, nos anos de 1867 e 1869; isto é, sem mencionarmos a vinda isolada de algumas pessoas ou grupos nos anos de 1839 e 1850. (GARDOLINSKI, 1956, p. 4).

Percebe-se a tentativa do pesquisador em relatar a chegada dos primeiros imigrantes poloneses no Rio Grande do Sul. Porém, a falta de material de pesquisa não comprova esta afirmativa, levando a crer que os imigrantes poloneses vieram durante $o$ maior número de imigrantes vindos para o Brasil no século XIX, juntamente com os demais imigrantes.

Precisamos considerar que uma das regiões da Polônia, que forneceu contingentes de colonos para o Rio Grande do Sul, era a Pomerânia (Pomorze) (pág. $82-1^{\circ}$ vol) e a Silésia (Slask) (página 91-idem). Grande parte destas regiões, densamente habitadas por poloneses foi anexada pela Alemanha durante os vários desmembramentos da Polônia. É bastante provável, pois, que os poloneses já fizeram parte das primeiras levas de emigrantes que se estabeleceram em S. Lourenço, perto de Pelotas (1857); 
Santa Cruz (1849); Santo Ângelo (1857); Ijuí e Guarani das Missões (hoje Guaramano) (1890). (GARDOLINSKI, 1956, p. 5).

Considerando, portanto, essa questão e a contar pelos sobrenomes, o fato de que muitos imigrantes que vieram com registros alemães, russos e austríacos eram poloneses, não nos restam dúvidas sobre a função exercida, ao chegarem ao Brasil, e especificamente ao Rio Grande do Sul: ensinar a língua alemã era necessário, pois os religiosos eram educados em Colégios austríacos (GARDOLINSKI, 1956). Com base em documentos fornecidos pelo IBGE (1950), Gardolinski faz uma estimativa dos diferentes imigrantes, com possível origem em matriz eslava, para o Rio Grande do Sul, entre 1885 a 1937 descrito na obra referida, desmistificando o marco do ano de chegada como 1890.

Quadro 2 - Chegada de imigrantes poloneses, russos, alemães e austríacos ao Rio Grande do Sul, entre 1885 e 1937

\begin{tabular}{|c|c|c|c|c|}
\hline $\begin{array}{c}\text { Ano de } \\
\text { chegada ao RS }\end{array}$ & $\begin{array}{c}\text { Número de } \\
\text { poloneses }\end{array}$ & $\begin{array}{c}\text { Número de } \\
\text { russos }\end{array}$ & $\begin{array}{c}\text { Número de } \\
\text { alemães }\end{array}$ & $\begin{array}{c}\text { Número de } \\
\text { austríacos }\end{array}$ \\
\hline 1885 a 1937 & 23.796 & 19.525 & 43.115 & 4.779 \\
\hline
\end{tabular}

Fonte: IBGE, 1950.

Se considerarmos as sobreposições de origem étnica e geográfica, conforme referenciado acima, é possível que o contingente polonês possa ter sido igual ou até maior que o contingente alemão, nos anos de 1885 a 1937, visto como o momento da "febre migratória no Brasil". Ou seja, recebimento de maior número de imigrantes em terras brasileiras. Como se vê, trata-se de uma realidade não visível nos bancos de dados, com relação aos imigrantes poloneses. Gardolinski (1956), ainda, analisa os registros de famílias imigradas para o Espírito Santo e Bahia, nos meados de 1871 a 1873.

Quadro 3 - Imigrantes poloneses registrados até 1889

\begin{tabular}{|c|c|c|c|}
\hline Paraná & Santa Catarina & kio Grande do Sul & Outros Estados \\
\hline 6530 & 750 & 300 & 500 \\
\hline
\end{tabular}

Fonte: GARDOLINSKI, 1956, p.16.

Através de relatos, entrevistas, visitas às comunidades, análise de documentos históricos, tem-se um quadro da presença dos imigrantes poloneses, os quais ajudaram na constituição do estado do Rio Grande do Sul. 


\subsection{Influências das Escolas polonesas}

Também vem de Gardolinski (1977) uma análise da influência das Escolas da colonização polonesa no Rio Grande do Sul na formação do Rio Grande do Sul, a partir de 1890. Era através da educação que poderiam garantir essencialmente uma melhora nas condições de vida, do mesmo modo, havia a necessidade de fundar sociedades e escolas que revelassem as características étnicas e suas procedências para constituir a identidade do imigrante que se estabelecesse no Brasil (GARDOLINSKI, 1977).

As próprias colônias construíam as escolas, sendo que era escolhido para professor o de saber notório, pois não havia apoio do governo e nem das prefeituras. Lembrando que, antes de aprender o português, os alunos tinham aulas em polonês para compreender, ler e escrever em sua língua materna.

\footnotetext{
Nenhuma geração teria sido privada das primeiras letras, pois, já nos últimos anos que precederam a nacionalização, todas as matérias de ensino eram ministradas em vernáculo; e somente na parte da tarde, como complemento, ensinavam-se rudimentos de ciência, religião e da língua polonesa. (GARDOLINSKI, 1977, p. 20).
}

É preciso ter em mente que a política de nacionalização do Estado Novo (19371945) tinha o intuito de converter todos os imigrantes poloneses em cidadãos brasileiros, com a expectativa de que pudessem se aculturar no que o Brasil tinha para oferecer e esquecer, deste modo, sua história, pátria e nação de origem.

Gardolinski (1977) examinou manuscritos, documentos, cartas, livros paroquiais, livros de atas de sociedades, livros de viagens, registros escolares, anotações de professores, calendários antigos de 1890 e 1901, revistas com publicação mensal, fotografias e depoimentos de pessoas. Assim, os dados chegam a um total de 128 escolas, perfazendo mais de 3.500 alunos disseminados pelo interior do Rio Grande do Sul.

\subsection{Imigrantes eslavos em Santa Catarina}

Para compreender as pesquisas sobre as línguas eslavas, em Santa Catarina, temse como exemplo o estudo de Maria do Carmo Goulart (1984), sobre os primeiros imigrantes poloneses que chegaram ao Porto de Itajahy e se instalaram na região do Vale do Itajaí-Açu.

O estudo de Goulart (1984) nos ajuda a compreender os processos migratórios de Santa Catarina para o Paraná. O registro da chegada dos poloneses ao Porto de Itajaí, segundo Goulart (1984), inicia-se em 1869. Isso fez com que os poloneses, por corresponderem o último grupo de imigrantes que chegaram à Colônia, juntamente com alguns italianos, tivessem que ocupar as terras que restaram, as zonas de mata, dificultando a permanência nessas áreas. Alguns poloneses como italianos, permaneceram trabalhando para os demais colonizadores, os alemães. Outro grupo, a partir de 1871, junto com Edmundo Wos Saporski, cognominado como "pai da imigração polonesa", usou desta estratégia para transferir os poloneses da Colônia de Brusque (Colônia Príncipe Dom Pedro) e levá-los a Curitiba.

Ao analisar os registros em cartório e identificar o batizado do primeiro polonobrasileiro nascido em terras catarinenses, Goulart (1984) desmistifica a tese de que os 
primeiros poloneses brasileiros teriam nascido no Paraná. São discursos correntes tanto em Santa Catarina, quanto no Paraná e no Rio Grande do Sul, em relação aos imigrantes eslavos. Para os estudos linguísticos, tais diagnósticos socioeconômicos dos processos históricos constituem subsídio para a descrição e interpretação da vitalidade das línguas eslavas.

\subsection{Os colonos eslavos no Brasil}

Em seu estudo sobre a afluência dos colonos eslavos no Brasil, Gluchowski (2005) retrata especificamente as alocações de cada imigrante, bem como suas contribuições para a configuração cultural e ocupação dos espaços, agricultura, política, educação, religiosidade e suas diásporas nas respectivas áreas de imigração. Em relação às línguas, o autor traz um retrato sobre a presença polonesa nas colônias, em especial em Santa Cândida, região metropolitana de Curitiba, em que analisa os costumes, vestimentas, cultura, características da população local.

Segundo Gluchowski (2005), é frequente o descendente, especialmente o jovem, deixar de falar na sua língua materna, o polonês, para falar a língua portuguesa. Assim, perde-se totalmente o que chama de polonismo. Ou seja, o sentimento nacionalista é retratado como característica do "novo mundo", em que se perde a nacionalidade original, para se constituir em outra nação.

$\mathrm{Na}$ leitura do texto, fica nítido que a língua representa uma questão secundária para o pesquisador, não no sentido de ser menos importante, mas sim, como parte dessa complexidade que é deixar de ser cidadão polonês, para se constituir como cidadão polono-brasileiro.

\subsection{Polaco ou polonês?}

Na pista dos processos históricos das línguas eslavas e em que se desenvolvem, tem-se ainda a contribuição dos estudos de Martins (2008), Iarochinski (2010), que ressaltam as características da cultura e da língua, incluindo o preconceito que sofreram os imigrantes eslavos em terras paranaenses.

Martins (2008) descreve a presença eslava na formação do município de Arapongas (PR). Especial atenção é dada às novas glebas formadas e organizadas desde 1937, em uma área distante $15 \mathrm{~km}$ da sede do município. Esse estudo enfoca basicamente uma gleba, preparada para receber poloneses, ucranianos e japoneses, a partir de um acordo entre Brasil e Polônia, em um período de ocupação intensa das terras no norte paranaense, nas décadas de 20 e 30 (MARTINS, 2008). Está claro que, nesses lotes divididos em alqueires, estabeleceram-se também mineiros, nordestinos, paulistas, além de imigrantes poloneses, ucranianos e japoneses. Na Gleba, a língua materna era importante para manter o sentimento nacionalista, pois preservando a própria língua se mantinha viva a identidade e as tradições de sua pátria.

Em seu estudo sobre "Polaco": identidade cultural do brasileiro descendente de imigrantes da Polônia, Iarochinski (2010) busca desmistificar o termo pejorativo polaco com que muitos se referem a descendentes dos imigrantes vindos da Polônia, os quais, segundo o pesquisador, há mais de 90 anos sofrem uma campanha sistemática pela eliminação da língua falada no país. Em tom de reação, ressalta a identidade de 
“polaco" desse imigrante polonês e recorre à etimologia, para justificar sua opção:

“A tradução de "polak" (que designa o nativo da Polônia), em todas as línguas latinas, com exceção do francês e romeno, é "polaco". Em Portugal [...], o único termo usado é "Polaco". Sendo desconhecido o termo "polonês". A rejeição equivocada abre espaço para que se elucide alguns aspectos da tradução literal e adequada do idioma "Polaco" para o português: Polska= Polônia; Polak= Polaco; Polaków= Polacos. $($ IAROCHINSKI, 2010, p. 4849).

Enfim, o autor busca, na literatura polonesa, em linguistas, filólogos, gramáticos como Cunha (1998) e Bagno (2001), bem como em definições de dicionários, a explicação para afirmar e reafirmar o uso do termo polaco como parte da identidade do descendente polonês. Por outro lado, os defensores do vocábulo "polonês" criaram um novo termo para designar a etnia polonesa, que é a designação "polônico" já muito referenciado em textos acadêmicos. Para Iarochinski (2010), este termo não faz sentido nenhum, pois em 2010 nem nos dicionários como Aurélio e Houaiss havia o registro.

Fica a pergunta se, para os estudos linguísticos, a definição de "polaco", "polônico" ou "polonês" serve como indicador da vitalidade linguística ou presença/manutenção da língua de imigração, ou ainda se há preconceito em relação à designação de "polaco" ou "polonês".

\subsection{Novamente, a oposição de sentido entre polaco x polonês}

É possível encontrar estudos pontuais mais específicos das línguas de imigração eslava. Um exemplo é o artigo de Cunha (1998) sobre "Alguns Etnônimos eslavos", em que se apresenta a definição, a origem e formação de eslavismos e correlatos no português, como mosco; moscovita; polaco; polonês; polônio; polono e ruteno. Cunha (1998) usou de transcritos dos séculos XVI, XVII e XVIII para explicitar a origem desses vocábulos. Esse tipo de análise fornece subsídios para o estudo das variedades existentes, em especial no uso do termo polaco, muitas vezes, visto como pejorativo. Oferecendo, assim, ao pesquisador múltiplas escolhas para adequar sua análise sobre uma base científica mais sólida. Reforçando que, os Etnônimos eslavos não são relevantes para a pesquisa, porém como parte da passagem histórica da presença polonesa no Brasil.

\section{Estudos sobre a vitalidade das línguas eslavas}

Ao delinear uma perspectiva de pesquisa linguística dos contatos de imigração eslava, as teorias podem ser as mais diversas, desde o campo descritivo ao aplicado, ou mesmo de uma análise micro para um campo de visão macrolinguístico. O presente artigo propõe-se justamente a clarear o estado da pesquisa, identificando áreas abrangidas, tópicos de interesse e, não poderia ser diferente, lacunas de pesquisa.

A vitalidade das línguas eslavas e sua presença na região Sul do Brasil em relação com os processos históricos parecem, no entanto, constituir o foco central do momento. O quadro-, a seguir, tenta resumir o cenário atual da pesquisa, que não tem a pretensão de ser um levantamento exaustivo, embora inclua o que se tem até o momento 
de mais significativo.

Quadro 4 - Pesquisas sobre as línguas eslavas

\begin{tabular}{|c|c|c|}
\hline Estudo & Área /Localidade & Tópicos de análise \\
\hline Delong \& Kersch (2014) & Cruz Machado - PR & $\begin{array}{l}\text { A presença das linguas eslavas/ Polonès } \\
\text { no contexto religioso }\end{array}$ \\
\hline Delong (2016) & $\begin{array}{l}\text { [Santa Faustina] } \\
\text { centro-sul do PR }\end{array}$ & Vitalidade linguística das linguas eslavas \\
\hline Maciel (2010) & $\begin{array}{l}\text { Itoupava Norte, em } \\
\text { Blumenau - SC, e } \\
\text { Benjamin Constant, } \\
\text { em Massaranduba - } \\
\text { SC }\end{array}$ & $\begin{array}{l}\text { Manutenção e ou revitalização da língua } \\
\text { polonesa }\end{array}$ \\
\hline Semechechem (2016) & Prudentópolis - PR & $\begin{array}{l}\text { A presença da língua Ucraniana- açōes de } \\
\text { bilinguismo }\end{array}$ \\
\hline Scholtz (2014) & $\begin{array}{l}\text { Virmond - PR e } \\
\text { Candói - PR }\end{array}$ & $\begin{array}{l}\text { Contato da lingua ucraniana e polonesa- } \\
\text { identidade linguistica das comunidades }\end{array}$ \\
\hline Wepik (2017) & $\begin{array}{l}\text { Áurea - RS e Nova } \\
\text { Erechim - SC }\end{array}$ & $\begin{array}{l}\text { Atitudes linguisticas/ crenças dos } \\
\text { descendentes poloneses }\end{array}$ \\
\hline Cunha (1998) & & $\begin{array}{l}\text { Definição dos etnônimos eslavos/ polaco } \\
\mathrm{x} \text { polonês }\end{array}$ \\
\hline $\begin{array}{l}\text { Mazurek \& } \\
\text { Wenczenowicz (2009) }\end{array}$ & Panorama brasileiro & $\begin{array}{l}\text { Inustraçăo bilingue português polonès } \\
\text { trajetória polonesa no Brasil }\end{array}$ \\
\hline Nadalin (2005) & Artigo & A sintaxe do polonês \\
\hline $\begin{array}{l}\text { Zdzislaw Malczewski } \\
\text { SChr (2008) }\end{array}$ & $\begin{array}{l}\text { Contexto brasileiro } \\
\text { da presença do } \\
\text { polonès }\end{array}$ & Paisagem linguística - ilustração bilingue \\
\hline
\end{tabular}

Fonte: Elaborado pela autora, 2019.

A primeira observação a fazer é que a maioria dos estudos levantados sobre línguas de imigração eslava surgiu nos últimos dez anos, coincidindo com o impulso dado pela política do inventário nacional da diversidade linguística (INDL). Junto com os estudos, vai-se delineando um quadro de formação de pesquisadores, especialmente no terreno da Sociolinguística e Dialetologia. Considerando as áreas e localidades abrangidas, têm-se ainda vazios significativos de pesquisa à descoberta. Até onde se sabe, não se tem igualmente um banco de dados significativo, como no caso do ALMAH (Atlas Linguístico-Contatual das Minorias Alemãs na Bacia do Prata: Hunsrückisch), que permita garantir o registro da língua, para uma descrição e revitalização futuras. Há carência de estudos descritivos da variação desse polonês, desse ucraniano, desse russo em "terras brasílicas", em parte modificados pelo contato com o português, que exigiria um conhecimento mais ativo dessas línguas por parte dos pesquisadores.

3.1 O uso da língua polonesa no contexto religioso e como constituição de 
O primeiro estudo analisado, de Delong \& Kersch (2014), assim como de Delong (2016), apresenta alguns aspectos relevantes sobre o uso da língua de imigração polonesa no contexto religioso como elemento de constituição da identidade. $\mathrm{O}$ estudo analisa o relato e a fala de um jovem padre polonês, na região de Cruz Machado - PR, sobre a presença e a vitalidade da língua polonesa na comunidade. Nessa comunidade, o padre reza uma vez por mês em polonês as missas, juntamente com os moradores de fala polonesa da região. Observa-se, ainda, portanto, certa vitalidade linguística no letramento litúrgico em polonês, ou seja, a manutenção da língua dá-se na esfera religiosa. Em 2014, época da entrevista, o referido padre já observava que algumas comunidades próximas não mais realizavam a liturgia na língua polonesa e que a presença de jovens não era significativa para manter a língua, já que, para ele, a língua não tinha prestígio e não "servia para muita coisa" (DELONG \& KERSCH, 2014, p.79).

Percebe-se, neste relato, que, apesar de o pároco usar a língua como manifestação de discurso e identidade, para justificar a presença da língua na comunidade, ele mesmo põe em dúvida seu valor como prática a ser mantida, isto é, que mereça uma ação relevante para manutenção das crenças e da língua polonesa na comunidade.

Já em sua tese, Delong (2016) aprofunda a análise da vitalidade linguística no contexto bilíngue, identificando as esferas em que a língua se mantém significativamente e sendo substituída pelo português. Para Delong (2016), a língua de imigração se fortalece na quantidade de práticas sociais e domínios em que ela está inserida, entre os quais enumera, em ordem de relevância, a religiosidade, o conhecimento dos falantes em relação à língua, o uso da língua em diferentes faixas etárias, o papel da mulher na transmissão dessa língua, a presença e manutenção através da geração acima de 55 anos, entre outros.

A pesquisa da língua minoritária, como se vê, foca-se neste estudo não só no contexto e circulação da língua, mas também na sua estrutura nas comunidades de uso e de fala, que garantem ou não sua manutenção pelos falantes. A isso se soma a compreensão do panorama das ações de política linguística observadas na comunidade, como, por exemplo, as aulas de polonês no CELEM (Centro de Línguas Estrangeiras Modernas). Essas aulas mostram-se insuficientes para manter a língua, pois os alunos fazem uso da língua polonesa, quando não estão em sala de aula. Delong (2016) conclui que a vitalidade da língua de imigração polonesa, nessa comunidade, mantém-se apenas através de eventos de letramento, tradições e costumes poloneses, onde a religião e a identidade desempenham papel central. Vê-se, portanto, que ações de promoção da manutenção de línguas minoritárias, como neste caso o polonês, mostram-se ineficazes, se não são assessoradas ou acompanhadas de práticas linguísticas que levem a essa promoção. Afinal, como se trata de uma prática de "Ensino de Língua Estrangeira", o polonês não é visto como língua materna. Não se trata primordialmente de discutir as ações metodológicas que compõem as práticas do CELEM, mas sim de analisar e considerar o contexto bilíngue em que estão inseridos os aprendizes.

\subsection{Língua polonesa em um contexto escolar, em Santa Catarina}

A presença do polonês no contexto escolar foi também o tema da dissertação de Maciel (2010). Neste estudo, realizado nas comunidades rurais de Itoupava Norte, em Blumenau - SC, e Benjamin Constant, no município limítrofe de Massaranduba - SC, 
mostrou que a língua de imigração polonesa foi usada especialmente no letramento litúrgico, na escola e em eventos culturais realizados em datas comemorativas. $\mathrm{O}$ objetivo principal desta pesquisa foi identificar os contextos de uso da língua, isto é, sua vitalidade linguística, determinando como seus falantes sinalizavam a possibilidade de uma proposta de manutenção e revitalização, já que nesse contexto há forte presença de falantes de alemão. Nesse contexto bilíngue português/alemão, polonês/alemão e português/polonês, o polonês apareceu na prática das escolas multisseriadas e nos cursos de idioma promovidos pela comunidade local. Alguns falantes do polonês, ao ingressarem na escola, iniciavam as aulas de alfabetização apenas falando no polonês "de casa", sendo que alguns também falavam alemão. Levando, assim, os próprios colegas de sala auxiliarem como intérpretes do português para o polonês.

Em 2007, as duas comunidades receberam uma professora vinda da Polônia, que ministrava aulas em polonês na igreja da Comunidade Benjamin Constant, no período de contraturno dos alunos de idade escolar. Além disso, havia também uma turma de adultos que participava das aulas no período noturno. Segundo os relatos dos entrevistados, foi um momento de muita participação na comunidade. Contudo, após o término do contrato da estagiária polonesa, que regressou à Polônia, as aulas foram encerradas. Percebeu-se, neste estudo, o desejo da comunidade de aprender a escrever na língua polonesa, mas a falta de investimento e apoio pelas organizações, tanto religiosa quanto política, impediu a continuidade das aulas.

Novamente, confirma-se a relevância do suporte institucional e social para garantir a execução das ações de language promotion. As ações de política linguística que não possuem esse suporte e não dão continuidade acabam se perdendo nos processos naturais de contato linguístico com a língua majoritária (CALVET, 2007).

\subsection{As práticas linguísticas}

As práticas linguísticas são tema central da tese de Semechechem (2016) sobre o Multilinguismo. O estudo se desenvolve em uma escola de comunidade ucraniana da área rural de Prudentópolis - PR. Ciente da presença ucraniana em seu entorno, a escola municipal usa de estratégias para manter essa língua de imigração como prática recorrente na escola.

Entre os recursos usados estão conversas informais, atividades lúdicas, atividades escritas, entre outros procedimentos selecionados de acordo com a série, idade e turma. Semechechem (2016) conclui, ao final, que as práticas linguísticas na escola da comunidade ucraniana da zona rural de Prudentópolis produzem ações multilíngues, em que a escola colabora na promoção da língua.

A pesquisa de Semechechem (2016) segue a etnografia da linguagem, para se aproximar dos informantes e compreender as práticas locais. Ao lado das práticas linguísticas, são também abordadas questões relevantes sobre as políticas linguísticas implementadas na comunidade, visando manter e "cultivar" a cultura e língua de imigração ucraniana. É curioso notar que, apesar da presença paralela do polonês, as práticas linguísticas são reforçadas exclusivamente em ucraniano, em todas as esferas da comunidade, envolvendo igreja, escola, grupos folclóricos, entre outros.

Se observa que a substituição linguística (language shift - FISHMAN, 2006) do ucraniano pelo polonês foi perdendo espaço e se tornando obsoleta na comunidade, na medida em que as ações e atividades de promoção do ucraniano foram se consolidando. 


\subsection{Descendentes de poloneses e ucranianos em contato com o português}

Contato semelhante entre as línguas de imigração polonesa e ucraniana foi estudado por Scholtz (2014), nas localidades de Virmond e Candói, no centro-sul do Paraná. Scholtz vale-se da teoria pluridimensional e relacional de Radke \& Thun (1996) para descrever aspectos da identidade linguística dessas duas comunidades plurilíngues, onde vivem falantes do polonês e do ucraniano. A pesquisa analisou os efeitos do contato polono-ucraniano e como uma língua exerce influência sobre a outra.

Os informantes da pesquisa eram todos falantes bilíngues polonês/português e ucraniano/português. Scholtz (2014) dividiu esses informantes em quatro grupos, "divididos por critérios socioculturais, ou de escolaridade formal (diastráticos), localização geográfica (diatópico), pela faixa etária (diageracional), pelo gênero (generacional)" (SCHOLTZ, 2014, p. 43). Com isso, chegou-se à seguinte matriz de entrevistas, seguindo o modelo em cruz de Thun (1998), que inclui os grupos CaGI e CaGII (parte superior) e CbGI e CbGII (parte inferior).

Fonte: THUN,1998, p. 711.

\begin{tabular}{c|c} 
CaGII & CaGI \\
\hline CbGII & CbGI
\end{tabular}

Figura 1 - Representação do modelo em cruz das dimensões de análise diastrática e diageracional, conforme Thun (1998)

A comparação horizontal entre os dados da geração mais velha (GII) e mais jovem (GI) permite uma análise de eventual mudança em curso. A comparação vertical entre falantes da classe mais e menos escolarizada $(\mathrm{Ca}$ e $\mathrm{Cb}$ ) aponta a influência da escolarização e do acesso ao português. Por fim, a comparação entre a cruz da localidade de Virmond com a de Candói permite avaliar os efeitos do contexto macrolinguístico. O Quadro 5, a seguir, resume esses diferentes cruzamentos nas respectivas dimensões de análise: 
Quadro 5 - Quadro de informantes das localidades pesquisadas

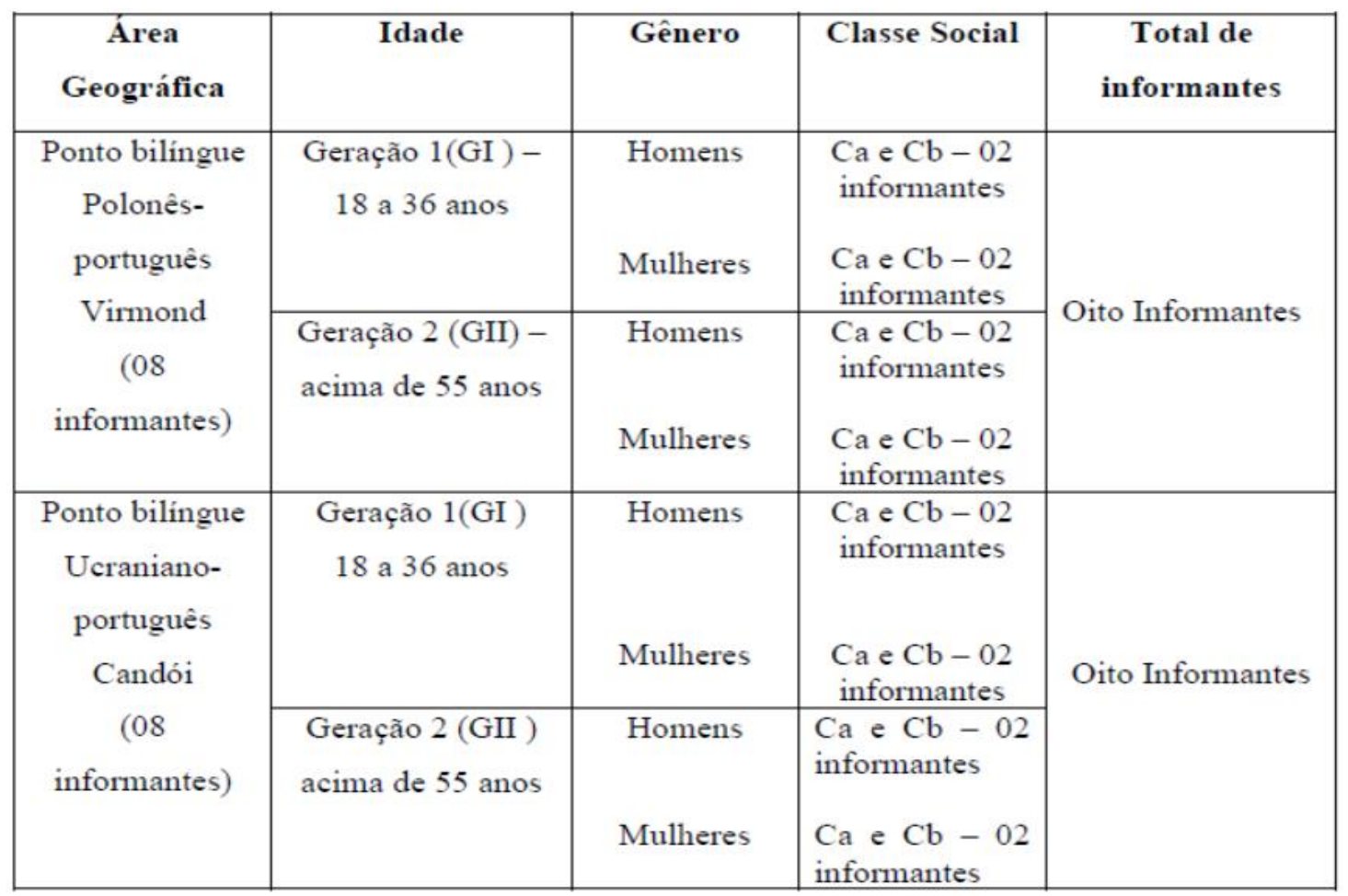

Fonte: SCHOLTZ, 2014, p. 46.

A coleta de dados, por meio da aplicação de questionário, revelou que o informante se identificava de diferentes modos com sua etnia/sua língua/sua identidade. Foi constatado, conforme Scholtz (2014), que embora os informantes se considerassem bilíngues, tanto português/polonês, quanto português/ucraniano, não faziam uso efetivo da língua minoritária. Assim, na falta da língua, a identidade foi expressa através de aspectos culturais, como festas, culinária ou respectiva religiosidade, muito mais do que pela língua. Esses resultados nos levam a refletir sobre as estratégias normalmente implementadas para a manutenção de uma língua.

\subsection{Crenças e atitudes linguísticas}

Em seu estudo sobre Crenças e atitudes linguísticas de polono-brasileiros de Áurea/RS e Nova Erechim/SC: o uso dos termos de parentesco, Wepik (2017) comparou o comportamento bilíngue variável de falantes polonês/português em uma colônia-mãe (Mutterkolonie), no Rio Grande do Sul, e seus descendentes na colôniafilha (Tochterkolonie), no oeste de Santa Catarina. Wepik (2017) correlaciona as atitudes linguísticas dos falantes com diferentes fatores extralinguísticos, englobando os parâmetros das seguintes dimensões: diatópica (Áurea/RS e Nova Erechim/SC), diageracional (GII [55 anos ou mais] e GI [de 18 a 36 anos]), diassexual (masculino e feminino) e diastrática ( $\mathrm{Ca}$ [com graduação completa ou cursando] e $\mathrm{Cb}$ [nenhuma escolaridade até o ensino médio]) (RADTKE \&THUN, 1996).

Para analisar adequadamente os resultados, o estudo leva em conta, além disso, 
aspectos ligados ao plurilinguismo, manutenção e substituição linguística, revitalização linguística e cooficialização. Vale salientar que o modelo teórico proposto nesses dois últimos estudos propicia uma visão macro, em que se buscam sínteses sobre o caminho ou o rumo que a língua minoritária está tomando na respectiva comunidade. Para tanto, foi utilizado um questionário metalinguístico, para análise das crenças dos falantes, além de um questionário lexical baseado nos termos de parentesco como indexalizador das tendências observadas na manutenção e/ou substituição da língua polonesa nos pontos de pesquisa. Depreende-se, nessas descrições, que os diferentes estudos linguísticos relacionados às línguas eslavas no Sul do Brasil contemplam cenários diversos, cada um com sua particularidade e significado para a pesquisa dessas línguas.

\subsection{Obras ilustradas bilíngues}

Existe um campo de estudo com interface histórica e linguística que é especialmente ilustrativo do contato do imigrante polonês e eslavo, de modo geral, com a natureza e sociedade brasileira. Um exemplo é o trabalho de Mazurek, Oliveira e Wenczenowicz (2009), traduzido e organizado por Márcio de Oliveira \& Thaís J. Tratase de uma obra ilustrada bilíngue polonês/português brasileiro que faz um retrato do colonizador polonês em terras brasileiras, desde o período da Colonização, em 1500, até a chegada de imigrantes de origem eslava no Paraná, seus personagens ilustres, poetas, entre outros que se radicaram no Brasil.

Fonte: MAZUREK, OLIVEIRA e WENCZENOWICZ, 2009.
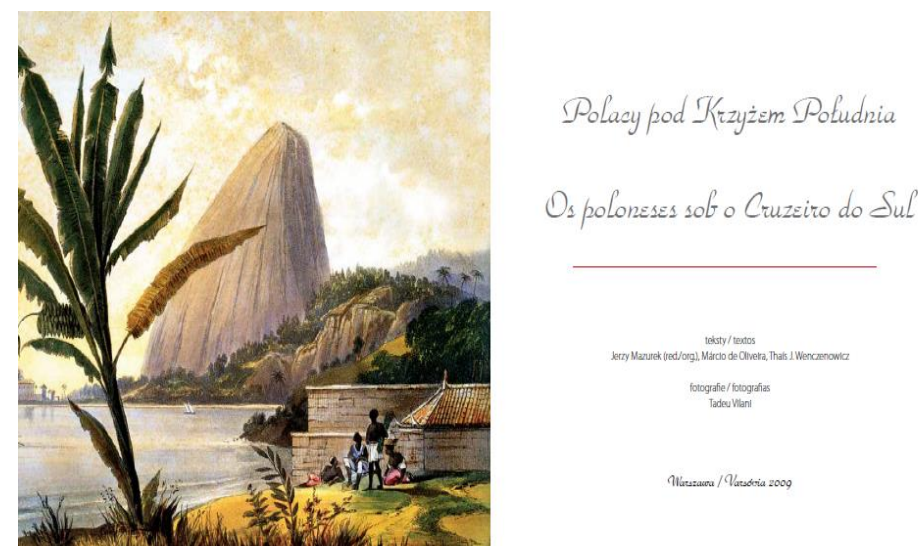

Figura 2 - Capa da representação do Brasil, no local de chegada dos imigrantes poloneses

Na primeira parte do estudo, os pesquisadores apresentam os literatos de relevância para o contexto brasileiro, entre os quais Jacob Pinheiro Goldeberg, Samuel Rawet e Paulo Leminski, representados na literatura e arte como símbolo de expressão e contribuição para a composição histórica dos poloneses no Brasil. Por meio de uma série de ilustrações, o estudo apresenta o cenário histórico da presença das línguas eslavas no Brasil.O texto bilíngue, em português e polonês, representa uma das ações de políticas linguísticas que levam a manutenção de uma língua minoritária. E, de certo modo, faz parte de 
planejamento linguístico que mantém a memória de mais de uma língua.

3.7 Paisagem linguística: presença visual da língua de imigração polonesa no Brasil

Na mesma linha do estudo anterior, Zdzisław Malczewski SChr (2008), escritor nascido na Polônia e naturalizado brasileiro, publicou em Varsóvia, em comemoração aos 140 anos de migração polonesa de Santa Catarina para Curitiba, um pequeno estudo sobre "Marcas da presença polonesa no Brasil". Através de imagens, homenagens de cidadãos polono-brasileiros em placas de ruas, instrumentos artesanais usados pelos descendentes poloneses no período da colonização, entre outros, a publicação apresenta a presença polonesa no Brasil. Pode se dizer que, em termos de pesquisa linguística, o estudo nada mais é do que o reflexo de uma paisagem linguística-linguistic landscape, (2006).

De significância para os estudos linguísticos, a paisagem linguística pode desmistificar a presença ou não de etnias na construção de uma identidade local, mapeando a diversidade linguística. O cenário histórico da presença polonesa aparece como um contexto bilíngue polonês/português que, segundo o autor, proporciona aos polono-brasileiros a oportunidade de compreender seu contexto linguístico e cultural na perspectiva de quem morou na Polônia e reflete sobre essas marcas na colonização do Brasil.

\subsection{Aspectos da sintaxe do polonês}

Em meio ao predomínio de temas do campo aplicado, o estudo de Nadalin (2005) aborda uma variável essencialmente linguística, como sugere o título “Aktionsart ${ }^{1}$ e aspecto verbal: uma análise dessa distinção no polonês". No centro da análise estão, portanto, os aspectos, temporal-verbal e sintático do uso do polonês, que se difere da constituição semântica das línguas germânicas. Como professor de polonês, Nadalin (2005) buscou com este estudo compreender a variação de significado no uso da composição gramatical dos verbos em polonês, os quais verbos perfectivos e imperfectivos. O Quadro 6 reproduz, neste sentido, a distribuição dos falantes das línguas eslavas em três grandes grupos.

\footnotetext{
${ }^{1}$ Modo de ação verbal. Traduzido por Nadalin (2005).
} 
Quadro 6 - Quadro de línguas e povos eslavos

\begin{tabular}{|c|c|c|c|}
\hline \multicolumn{2}{|r|}{ Povos eslavos } & Línguas eslavas & Referências geográficas \\
\hline \multirow{5}{*}{$\frac{\varrho}{5}$} & Grupo & Polonês & Varsóvia (Polônia) \\
\hline & Lechítico & Cassúbio & Norte da Polônia (cercanias de Gdańsk) \\
\hline & Grupo & Tcheco & Praga (República Tcheca) \\
\hline & Tcheco-eslovaco & Eslovaco & Bratislava (Eslováquia) \\
\hline & Grupo Lusácio & Lusácio /Sorábio & $\begin{array}{l}\text { Chociebuż (Cottbus) no Brandeburgo, } \\
\text { Budziszyn (Bautzen), na Saxônia } \\
\text { (A lemanha) }\end{array}$ \\
\hline \multirow{3}{*}{ 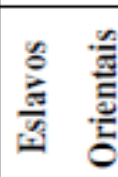 } & Ucranianos & Ucraniano & Kiev (Ucrânia) \\
\hline & Bielo-russos & Bielo-russo & Minsk (Bielo-rússia) \\
\hline & Russos & Russo & Moscou (Rússia) \\
\hline \multirow{5}{*}{$\frac{0}{\bar{E}}$} & \multirow{3}{*}{$\begin{array}{c}\text { Esloveno e Servo- } \\
\text { croata }\end{array}$} & Esloveno & Liubliana (Eslovênia) \\
\hline & & Sérvio & Belgrado (Sérvia) \\
\hline & & Croata & Zagreb (Croácia) \\
\hline & Grupo Búlgaro e & Búlgaro & Sofia (Bulgária) \\
\hline & Macedônio & Macedônio & Skopje (Macedônia) \\
\hline
\end{tabular}

Fonte: NADALIN, 2005, p. 8.

O quadro 6 é complementado com o número de falantes dessas línguas eslavas: a língua mais falada é o russo, segundo Nadalin (2005), mais de 114.000 .000 de falantes. Em segundo lugar, vem o ucraniano com cerca de 49.000 .000 de falantes e, por último, o polonês com cerca de 35.000 .000 de falantes. Nadalin (2005), contudo, não faz referência ao número de falantes no exterior, uma vez que há falantes de línguas eslavas nos Estados Unidos, Austrália e no Brasil.

O estudo conclui que, apesar de opiniões contrárias como a de Verkuyl (1999) e Bertinetto (2001), a distinção existe no que se refere à língua eslava polonesa e em menor proporção na língua eslava russa.

[...] Nesse sentido, discutiu-se uma série de dados dessa língua eslava, a partir do diálogo de duas abordagens: Verkuyl (1999) e Bertinetto (2001). [...] iniciou-se com a apresentação da proposta de Verkuyl, que não considera necessária a distinção entre as duas categorias em questão. [...] Concluindo que a abordagem composicional de Verkuyl embora dê conta de explicar uma série de fenômenos relacionados ao aspecto verbal em polonês, também deixa algumas questões sem resposta [...] (NADALIN, 2005, p.121).

No estudo de Nadalin (2005), o pesquisador argumenta sobre o uso dos verbos nas línguas eslavas, em especial o polonês, e que se faz necessário ponderar sobre esses aspectos distintos no uso da língua. Além de assimilar as evidências entre essas duas categorias e reforçar o que se afirma em relação a algumas línguas, os indícios são 
nítidos em relação ao polonês, a Aktionsart (modo de ação) e o aspecto verbal que podem convergir no uso dos verbos.

O estudo de Nadalin (2005), embora não analise diretamente a língua de imigração eslava efetivamente falada, permite refletir sobre os aspectos linguísticos observáveis no contato português-polonês-ucraniano etc., nos diferentes níveis fonéticofonológico, léxico-semântico, morfossintático e mesmo pragmático ou discursivo.

\section{Considerações finais}

A tentativa de contrapor e complementar estudos da história da imigração eslava e estudos com foco nas línguas de imigração eslava sugere carências ainda muito acentuadas na pesquisa, muito mais no campo de descrição linguística. Não obstante, os impulsos observados nos últimos anos dão prova de que há avanços, mesmo que ainda muito tímidos. Este artigo procurou visibilizar e diagnosticar o quadro atual. A ênfase tem recaído em questões sobre a vitalidade, uso e revitalização das línguas de imigração eslava no Brasil.

A discussão na perspectiva da descrição da vitalidade linguística das línguas de imigração eslava, especialmente polonesa, assim como as ações de promoção e revitalização linguística, aponta para algumas metas que, em tom de conclusão, vale mencionar aqui: 1) a formação de pesquisadores dessas línguas e consequente surgimento de grupos e redes de pesquisa que conectam não apenas instituições e programas de pós-graduação em regiões distintas, como também as diferentes línguas eslavas, no intuito de reunir esforços; 2) a necessidade de mapeamento das áreas e localidades de presença de línguas de imigração eslava, distinguindo os diferentes grupos de fala polonesa, ucraniana, russa, entre outras; e 3) a criação de bancos de dados das diferentes variedades trazidas pelos imigrantes. Esta tarefa inclui não apenas o levantamento bibliográfico, mas, ainda, o intercâmbio de conhecimento, no sentido de uma eslavística contatual brasileira.

\section{REFERÊNCIAS}

ALTENHOFEN, Cléo Vilson; THUN, Harald. A migração e os contatos linguísticos na geografia linguística do sul do Brasil e Bacia do Prata. In: AGUILERA, Vanderci de Andrade; ROMANO, Valter Pereira. A geolinguística no Brasil: caminhos percorridos, horizontes alcançados. Londrina: Eduel, 2016. p. 371-392.

BAGNO, Marcos. Preconceito Linguístico. São Paulo: Ed. Loyola, 2001.

BERTINETTO, P. M. On a Frequent Misunderstanding in the Temporal-Aspectual Domain: The 'Perfective-Telic Confusion'. In: CECHETTO, C. et al. (org.). Semantic Interfaces: reference, anaphora and aspect. Standford, Califórnia: CSL Publications, 2001. p. 117-210.

BYTSENKO, Anastassia. Imigração da Rússia para o Brasil no início do século XX. Visões do paraíso e do inferno. Tese de Doutorado - Universidade de São Paulo - 
Faculdade de Filosofia, Letras e Ciências Humanas, Departamento de Letras Orientais, Programa de Literatura e Cultura Russa, 2006.

CALVET, Louis. Jean. As políticas linguísticas. São Paulo: Parábola, 2007.

CUNHA, Antônio Geraldo da. Alguns etnônimos eslávicos (estudo históricoetimológico). Filologia e Lingüística Portuguesa, n.2, p. 143-157, 1998.

DELONG, Silvia Regina; KERSCH, Doroteia Frank. Perfil de descendentes de poloneses residentes no sul do Brasil: a constituição da(s) identidade(s). 2014. 21p. Disponível em:

http://www.seer.ufu.br/index.php/dominiosdelinguagem/article/view/26418/15193. Acesso em: 28 jun. 2018.

DELONG, Silvia Regina . Vitalidade linguística e construção de identidades de descendentes de poloneses no sul do Paraná. Tese (Doutorado) - Universidade do Vale do Rio dos Sinos, Programa de Pós-Graduação em Linguística Aplicada, São Leopoldo, 2016. 212 p. Disponível em:

http://www.repositorio.jesuita.org.br/handle/UNISINOS/6105. Acesso em: 28 jun. 2018

FISHMAN, Joshua Aaron. Language maintenance, language shift, and reversing language shift. In: BHATIA, Tej K.; RITCHIE, William C. (eds.). The handbook o bi/ingua/ism. Malden; Oxford: Blackwell Publishing Ltd, 2006. p. 406-436.

GARDOLINSKI, Edmundo. Imigração e colonização polonesa. In: BECKER, Klaus (Org.). Enciclopédia Rio-grandense. v. 5. Canoas: Regional, 1956. p. 1-104.

Escolas da colonização polonesa no Rio Grande do Sul. Porto Alegre: Escola Superior de Teologia São Lorenço de Brindes-ESTSLB. Caxias do Sul: UCS, 1976, 138p. Universidade de Caxias do Sul, co-editado 1977.

GARIN, Podolano Felipe. Imigração Ucraniana em Curitiba. Trabalho de Conclusão de Curso de Ciências Sociais - Ciências Humanas, Letras e Artes, Universidade Federal do Paraná, 2010.

GLUCHOWSKI, Kazimierz. Os poloneses no Brasil: Subsídios para o problema da colonização polonesa no Brasil-Edição histórica. Trad. De Mariano Kawka, Porto Alegre: Rodycz \& Ordakowski Editores, 2005.

GORTER, Durk. Linguistic Landscape. A New Approach to Multilingualism. Great Britain: Datapage Ltd, 2006.

GOULART, Maria do Carmo Ramos krieger. Imigração (A) Polonesa nas Colônias Itajhay e Príncipe Dom Pedro: Um contribuição ao estudo da imigração polonesa no Brasil Meridional. Blumenau: Fundação “Casa Dr. Blumenau”, 1984.

IAROCHINSKI Ulisses. Polaco - Identidade Cultural do Brasileiro descendente de 
imigrantes da Polônia. Curitiba, 2010. p.200.

INSTITUTO BRASILEIRO DE GEOGRAFIA E ESTATÍSTICA (IBGE). Estudos sôbre as Línguas Estrangeiras e a Aborígenes faladas no Brasil. Rio de Janeiro: Estatística Cultural, 1950.

MACIEL, Myrna Estella Mendes. Línguas de imigrantes: a língua polonesa na Região Sul do Brasil. Dissertação de Mestrado - Curso de Mestrado em Ciências da Linguagem - Universidade do Sul de Santa Catarina (UNISUL), . Florianópolis, 2010.

MARTINS, Cláudia Regina Kawka. A presença eslava na formação de Arapongas. Curitiba, PR:Vicentina, 2008.

MAZUREK, Jerzy; OLIVEIRA, Márcio de; WENCZENOWIC, Thaís J. Polacy pod Krzyżem. Os poloneses sob o Cruzeiro do Sul. Warszawa, Varsóvia: Biblioteka Ibercryska, 2009. $117 \mathrm{p}$.

NADALIN, Eduardo. Aktionsart e Aspecto verbal: Uma análise dessa distinção no polonês. Dissertação de Mestrado - Letras - Área de concentração em Estudos Linguísticos, Curso de Pós Graduação em Letras - Ciências Humanas, Letras e Artes, Universidade Federal do Paraná, 2005.

SCHOLTZ, Adriana. Jesus. Identidade linguística: descendentes de poloneses e ucranianos em contato com o português em Virmond e Candói, no Paraná. Dissertação de Mestrado - PPGEL, UFFS, Chapecó, 2014.

SEMECHECHEM, J. A. O multilinguismo na escola: práticas linguísticas em uma comunidade de imigração ucraniana no Paraná. Tese de Doutorado - Universidade Estadual de Maringá, Programa de Pós-Graduação em Letras, Maringá, 2016. Disponível em: http://www.ple.uem.br/defesas/def_jakeline_aparecida_semechechem_do.htm. Acesso em: 24 jun. 2019.

RADTKE, Edgar \& THUN, Harald (Eds.). Neue Wege der romanischen Geolinguistik: Akten des Symposiums zur empirischen Dialektologie. Kiel: Westensee-Verl., 1996. 648 p. (Dialectologia Pluridimensionalis Romanica; 1.)

THUN, Harald. La geolingüística como lingüística variacional general (com ejemplos del Atlas lingüístico Diatópico y Diastrático del Uruguay). In: INTERNATIONAL CONGRess of Romance Linguistics AND PhILOLOGY (21: 1995: Palermo). Atti del XXI Congresso Internazionale di Linguistica e Filologia Romanza. Giovanni Ruffino. Tübingen (Org.). Niemeyer, 1998. v. 5, p. 701-729.

VERKUYL, Henk Johannes. Aspectual Issues: studies on time and quantity. Stanford: CSLI Publications. 1999. 266 p.

WEPIK, Fernanda. Fátima. Crenças e atitudes linguísticas de polono-brasileiros de Áurea/RS e Nova Erechim/SC: o uso dos termos de parentesco. Dissertação de 
Mestrado - PPGEL, UFFS, Chapecó. 2017.

ZDZISŁAW Malczewski SChr. SLADY POLSKIE W BRAZYLII. MARCAS DA PRESENÇA POLONESA NO BRASIL Warsawa, 2008. Disponível em:

https://www.iberystyka.uw.edu.pl/ Acesso em: 26 jul. 2019. 